\title{
BIJDRAGE TOT DE KENNIS DER OUDJAVAANSCHE LE'TTERKUNDE.
}

DOOR

Dr. H. H. JUYNBOLL.

Bij het lezen van de Oudjavaansche handschriften, die wijlen dr. H. N. van der Tuuk an de Leidsche Universiteitsbibliotheek vermaakt heeft, is mij gebleken, dat de inhoud van vele dezer geschriften hetzij direct of indirect aan het bekende Indische epos Mahâbhârata ontleend is. In het kort wensch ik dit aan te toonen, waarbij ik de Oudjavaansche prozabewerking van het Mahâbhârata en het epos Bhâratayuddha buiten beschouwing zal laten. Alleen valt hieromtrent op te merken, dat behalve de HSS. die Prof. Vreede reeds genoemd heeft in zijnen Catalogus der Jav. en Mad. HSS. p. 387-388 en die nader door mij beschreven zijn in mijn academisch proefschrift "Drie boeken van het Oudjavaansche Mahâbhârata" (inleiding, pag. 4-31), het legatum Warnerianum thans nog 4. HSS. van het O. J. Âdiparwan, 3 volledige van het Wirâtaparwan, 4 van het Udyogaparwan, 3 van het tot dus verre nog onbekend geblevene Bhîșmaparwan, 3 van van het Âçramawâsaparwan, 3 van het Mosalaparwan, 3 van het Prasthânikaparwan en 4 van het $\mathrm{S}$ wargârohanaparwan ontvangen heeft. Ook het aantal HSS. van het Bhâratayuddha, dat in Prof. Vreede's Catalogus (p. 2-10 en 392) slechts 6 bedraagt, is thans gestegen tot 26. Na nog vermeld te hebben, dat het legatum Warnerianum verrijkt is met 4. HSS. van het gedicht Hariwangça, terwijl Prof. Vreede l. c. p. 393 er slechts één beschreef, ga $\mathrm{ik}$ thans over tot de behandeling der gedichten, die tot nu toe in Europa nog niet bekend waren. Gemakshalve zullen zij in alphabetische volgorde beschreven worden.

I. Ghațotkacâçraya of Ghațotkacaçaraṇa. De laatste titel komt voor in het eerste vers van zang 50 :

Sâmpun kekĕtan ing kathâtita Ghaṭotkacaçaraṇa ngaranya tanparacana. 
In zang 51 en aan het slot van dit gedicht wordt het echter Ghaṭotkacâçraya genoemd. De naam van den dichter is $\mathrm{Mpu}$ $\mathrm{Panuluh}$ (zang 50, vs. 1). Dit gedicht is niet alleen belangrijk, omdat het in zuiver Oudjavaansch geschreven is, maar voorals wegens zijn inhoud. Het is n.l. een der bronnen, waaruit de Maleiers hunne wayang-verhalen geput hebben. Dr. van der Tuuk zegt in zijne inleiding op de door hem toegelichte Maleische wayang-verhalen (T. I. T. L. Vk. XXV, p. 488, "de meesten echter blijken vertalingen te zijn van werken, die heden niet meer op Java schijnen te bestaan." De inhoud van het Oudjav. gedicht wordt gevormd door de beschrijving van den strijd tusschen Abhimanyu, den zoon van Arjuna, en den Korawa Lakṣaṇakumâra om het bezit van Kṣitisundarî, waarbij de zoon van Bhîma, genaamd Ghaṭotkaca, zijnen neef te hulp komt. Deze geschiedenis komt in dr. van der Tuuk's vertaling of inhoudsopgave van de Maleische geschiedenis der Pandawa's (T. I. T. L. Vk. XXI) voor op blz. 10 tot 14. In het Maleische HS. 3195 a, door mij beschreven in mijnen Catalogus der Mal. en Sund. HSS. pag. 50-51, vindt men deze episode van pag. 16 tot pag. 49. Ook in andere Maleische wayangverhalen, b. v. in cod. 3221 en 3244 (beschreven 1. c. pag. 52-54 en pag. 54-56) vindt men dezelfde geschiedenis. Door vergelijking met het O.J. gedicht kan men sommige eigennamen in de Maleische ḥikâyat's verbeteren, b.v. Siti Sundari, waarin men Siti voor het Maleische ستى zou houden, blijkt verbasterd te zijn uit Skr. Kṣitisundarî; Laksamana Kumara uit Skr. Lakṣanakumâra; Djarudi uit Juru dyah ${ }^{1}$ ), d.i. praefectus muli eru m ;b.v. Ghat. zang X, vers 7; XI, vers 12 en 14; XXVI, 2 enz.)

Het bezoek van Abhimanyu bij de godin Durgâ (vgl. v. d. Tuuk's vertaling l. c. pag. 11 en cod. $3195^{\text {a }}$, pag. 33 sq.) is in het Oudjav. gedicht in zang 31 beschreven. Op blz. 4,2 (l. c.) noemt dr. v. d. T. onder de namen van hen, die aan de Korawa's tegenstand bieden, Baladewa. Daar deze echter een bondgenoot der Korawa's is, kan hij niet bedoeld zijn. Blijkbaar heeft ook dr. v. d. T. dit opgemerkt, want achter dezen eigennaam heeft hij een vraagteeken geplaatst. Op p. 42 van cod. 3195 a leest men

1) Het Nieuwjavaansche woord anqaаarnang is eene verbastering van O.J. kadyahan en niet afgeleid van Skr. deha, zooals Prof. Roorda vermoedt (Wajangverhalen, p. 474). 
in plaats van Baladewa Basudewa (vgl. mijnen Catal. der Mal. en Sund. HSS. pag 50). Deze lezing nu wordt bevestigd door vers 2 van zang 4.0 :

Sirang Ugrasena Basudewa ratu matuha tanggwan ing naya,

Kṛtadharma Satyaki sang Uddhawa patih adhikâra ring guṇa.

Tevens blijkt hieruit, dat men in plaats van Patih Uduwirah (v. d. T. l. c.) Patih Uddhawa lezen moet, zooals dr. v. d. Tuuk reeds opmerkte op pag. 12 (l. c.). Deze patih komt behalve in het Bhomakâwya (pag. 8) ook voor in het Mosalaparwan (pag 72 van mijn proefschrift "Drie boeken van het O.J. Mah.").

II. Ha riwija y a. Omtrent dit O.J. gedicht zegt dr. van der Tuuk in zijn Kawi-Balineesch woordenboek, I, pag. 90, s. v. hari: "titel van een kakawin". Verder verwijst hij naar ratmaja. Dit is (l. e p. 739) de "eigennaam van een râkṣasa, die in Hr. het a mṛta steelt, en door de goden onder aanvoering van $\mathrm{Kumâra}$ wordt bestreden en door Wiṣṇu gedood.; W. ontfutselde hem het amrta, na zich in eene godin veranderd te hebben." Daarna haalt dr. v. d. T. de overeenkomstige plaats uit het Âdiparwan aan, die gedeeltelijk door dr. Brandes (Not. Bat. Gen. 1894) en gedeeltelijk door schrijver dezes uitgegeven is (B. T. Vk. $6^{\text {e }}$ volgr. I, pag. 83). Ook verwijst dr. v. d. Tuuk naar A kûpara, volgens pag. 147 s. v de "eigennaam van een schildpad bij het karnen van de zee." Dan volgt de plaats uit het Âdip., die men bij dr. Brandes (l.c.) op pag. 3 v. d. overdruk en in mijne vertaling (l. c.) op blz. 90 vindt. Verder: "aku pâdhirâja krijgt die schildpad, onder den voet van de Mandara, van de karnende goden tot naam. Hr. 2-2, 12."

Uit het bovenstaande blijkt duidelijk, dat de inhoud van dit gedicht gevormd wordt door de mythe van het karnen van de Melkzee, die aan het Âdiparwan ontleend is, gelijk men weet. Dit volgt ook uit zang $\mathrm{I}$, vs. 2, regel 3 :

Nduk Kṣînânṇawa tatwa nguni pinutĕr prawara giri Mahendra sâdhana, (ten tijde, toen vroeger de Melkzee gekarnd werd, waarbij de voortreffelijke berg Mahendra als hulpmiddel diende.) In zang I wordt verhaald, hoe de goden en asura's zich naar de Mandara begeven, die door Anantabhoga naar de Melkzee gesleept wordt, evenals in het Âdip. Van Akupa is sprake in vers $12 \mathrm{c}$ van zang II: 
Kyâting rât ng Akupâdhirâja tinĕhĕr de sang watěk dewata. Inmijne verhandeling ${ }^{1}$ ) over "de mythe van den berg Mandara in de Javaansche letterkunde." (B. T. L. Vk. $6^{\text {e }}$ volgr. I, pag. 81, n. 1 ) is door mij reeds gewezen op vers 1122 van het Sanskr. Adip., om te bewijzen, dat A kupa eene verbastering is van Akûpâra. Bâsuki wikkelt zich om de zijde van den berg (vers 13). In zang IV, vers 4 , overeenkomende met çloka 1146 van het Indische Adip. wordt het ontstaan van Lakṣmî of Çrî en inzang $\mathrm{V}$, vers 1 , regel 4 de geboorte van $\mathrm{Dh}$ anwatari beschreven (vgl. çloka 1149) in deze woorden:

Singgih sâri ni çṛți ning jaladhi parwwata tumuluy adadya Dhanwantari.

In vers 6 van zang 28 wordt verhaald, hoe an den vorst der Asura's, genaamd Ratmaja, door Wiṣnu de gedaante van Lakṣmî de a mṛta ontfutseld wordt. De eigennaam Ratmaja ontbreekt in het Oudjavansche Âdip., doch komt voor in het gedeelte van de O.J. cosmogonie Tantu Pangge̊laran, dat door Prof. Kern uitgegeven ${ }^{2}$ ) en door schrijver dezes vertaald is (B. T. L. Vk. $6^{\mathrm{e}}$ volg. I, pag. 92). Daar vindt men naast Ratmaja eene $R$ a t $\mathrm{n}$ ajî, waaruit men zou opmaken, dat deze plaats van den Tantu van jonger datum is.

In de volgende zangen wordt de strijd der goden en daemonen beschreven. Indra roept daarbij Wiṣnu's hulp in (zang 49, vers 14). In vers 31 leest men, hoe Wiṣnu den asura-vorst Bali verslaat. De bekende geschiedenis van $\mathrm{R} a \mathrm{hu}$ begint in zang 55 met deze woorden :

W(w)antĕn pwâsura dânawâdhika ngaranya Râhu k a rĕng ö. ${ }^{3}$ )

Het overeenkomstige gedeelte van het Âdip. is door mij met eene vertaling uitgegeven (l.c. pag. 85 en 87). De naam van Râhu's vader die in het Indische Âdip. Wipracitti luidt, is hier, evenals reeds in het O.J. Âdip., verbasterd tot Wipracinti. De titel van dit gedicht blijkt uit vers 1 van zang 58 .

III. Kṛşnântaka. Het begin van dit gedicht is reeds uitgegeven in deze Bijdragen (6 $6^{\mathrm{e}}$ volgr. VI, pag. 214 vgl.). Daar ik

1) Hierin verzuimde ik melding te maken van den lakon Jamur Dipa (zie Prof. Vreede's Cat. der Jav. en Mad. HSS. cod. 1979, nº. 146), die ook voorkomt in cod. 3419c (leg. v. d. Tunk). pag. 23-31.

$\left.{ }^{2}\right)$ B. T. L. Vk. $5^{\circ}$ volgr. II, pag. 584 .

3) Zie het vervolg in het aanhangsel hierachter. 
mij voorstel ook het vervolg van dit gedicht later bekend te maken, is het voldoende, hier mede te deelen, dat het eene vrije metrische bewerking van de vier laatste boeken van het Mahâbhârata (Âçramawâsa-, Mosala-, Prasthânika- en Swargârohaṇaparwan) bevat.

IV. Ratnawijaya. Omtrent dit gedicht zegt dr. van der Tuuk in zijn Kawi-Bal. Wdb. I, pag. 737-738; s. v. ratna: "titel van een kakawin, behelzende 't gevecht van Sunda en Upasunda om Tilottamâ, op hen afgezonden, daar zij door strenge boetedoening zoo machtig geworden waren, dat zij zelfs Indra bedreigden; in de taal (heerscht) groote vrijheid, zoo b.v. lottama in plaats van Tilottamâ; uit duloma (is) op te maken, dat het getrokken is uit de reeds bedorven Âdip."

Het gedicht begint met deze woorden (zang I, vers 3, regel 2):

Wwantěn daitya mahaprabhâwa karĕngö wěka-wĕka [danujendra wîriy yawân, Kyâti'ng rât Upasunda Sunda pangaranya'n asanak [atikambarât adbhuta.

De verbastering van Tilottamâ tot lottama komt voor in zang XVIII, vers 4 , regel 2 :

Nâhan hetu si ratna lottamâ ngaranya tĕkap ira bhațâra tan waneh.

Men kan dit licht herstellen, door in plaats van si ratna te lezen sirâ'n Tilottamâ, waarbij de versmaat behouden blijft.

De titel van het gedicht blijkt uit vers 5 van zang 22:

Nâhan hîngan iking kathâ pratita Ratnawijaya pangaranya tan waneh.

De woorden tan waneh (niet anders, geen ander) zijn slechts als een stoplap metri causa te beschouwen. Over het origineel van dit verhaal vergelijke men de voorrede van Bopp, Ardschuna's Reise zu Indra's Himmel, p. XV, zijne vertaling l.c. pag. 45 en L. v. Schröder, Indiens Literatur and Cultur, pag. 494-495.

Ten slotte volgen hier nog de Oudjav. tekst van zang 55 van den Hariwijaya wegens de belangrijkheid der legende, die het ontstaan van zon- en maaneclipsen verklaart, en ter vergelijking met het Âdiparwan : 
Wwantĕn pwâsura dânawâdhika ngaranya Râhu karĕngö, parṇnahnyâtmaja Wipracinti aniwâryya ring suraripu, krûrâgöng awugah ya göng galak anâgateng surawara. (1) Ngûnî kâla nikang prang adbhuta pijĕr ya tan hana mahas, çîrṇna dhwasta tikang tapowana těkapnya durbbala rurah, sangsiptan ri yulihnya mogha maputĕk mhâh salahasa, yar ton bhrasta nikang swagotra mamangun galak mangabaran (2) Nâ sambandha nikâtiçîghra tumuluy mareng Haripada, an sâmpun rumĕngö ring utsawa ning âmṛta prakaçita, byaktâmanggnha kâladeça ling ikâ tatön amalěsa, wet ning göng nikanang kamânawibhawanyâ tanpasapihan. (3) Kâlanya'n datĕng ing sabhâ ndan amasang ta bañcanamaya, ngkâ dewâkṛti çântarûpa tĕmahanya mĕnggĕp ahalĕp, jâti krûra inâryyakĕnya ri kaçaktyan ing jutimaya, tâtan sangçaya lingnya milwa manginum ring âmṛta wara (4). Ewĕh ngwang makire pramoha ri bhațâra munggu ri dalĕm, sûkșmekâra anâdhisûkșma hiběk ing triloka maganal, sâkșât wyâpaka tan dadînapakarî hị̣ĕp ning adhama, kâhinyan apacâra ghâțaka kațungka buddhi mahala. (5) Âpan hyang sawitâdidewa wara candramâparimita , sakṣyânggěh nira lingga sûkșma umarikṣakĕn sabhuwana, ndah mâjar ta sire upendra hana dușta milwa mangimûr, tar wruh yan panginum warâmṛta rumuddha kâryya kuṭila (6). Nâhan pâjar irâtigadgada bhațâra Wiṣnu rumĕngö, "Cehâhâh druhakâtidûrtta mawalepa nitya kujana, tan wring mâryyada nîca dambha paracidra cora macĕmĕr, tan mâryyângapakâra kimburu mamighnakĕn parahita (7). Tar ton bhrașta hilang sawargga nika dengku ngûni ring ayun, mangkin wâdhaka ta surud ndya ta paranya dadya luputa,“ Nâhan ling nira Padmanâbha ri dalĕm twas arddha wuyûng, hetunya n pangalap ta cakra nira tikṣna mâya dumilah (8). Âmbĕk çrî Narasingha sâhasika mangkas-angkas asiga, yekân çîghra sudarççanâstra lumĕpas sake tamuduhan, tar wruh tekana tang mahâsura cĕngĕlnya sep katariwal, kombul bhîșana mastakanya tĕka ring nabhastala mĕsat. (9). Lindû cañcala tang mahîtala těkeng Himâdri gumiwang, Sangke göng nikanang kawandha nika rodra parwwatasama, tampuhnya'n gumtĕr tibê magulingan datan pabisa ya, ndan tĕṇdasnya jugâhurip kadi glap ya manghruk agalak (10). Panglingganya hilî ning âmṛta tkeng gulûnya niyata, krûrâkâra makin lwir Antaka mahâ masĕnghit anguhuh; "Candrâditya ayay palalwakna yatna ko jaga-jaga; "toh tanggap pamalĕskwikanyu niyata mwa çînṇna gilutĕn (11). 
"Sângsârangkwiki demu mohita wineh tkapku maluya, "nâ hetunya pahenakĕn tiku manahmu haywa malara. "âpan [h]îrsya ya doumwamah salahasangkwi kon mapakna, "tâ de kanyu dlâha duḥka pangang ̌ngkwa de mwa kuhira" Ling ning dânawaçirșa rodra [h]umaku'ng glĕngnya ri sira, ngkân lunghâ ta ya ring nabhastala wisâta sûkṣma mangawit, âçâçoka ta sang minangkana manah nirepu kapgan, marmmâ çrî Puruṣottamâmalĕh akou tatan kaparihan (13).

A a nteekeningen.

Karĕngö komt dikwijls op eene dergelijke wijze achter een eigen naam voor. Dr. van der Tuuk. (Kawi-Bal. Wdb. I, pag. 817) houdt het voor eene vertaling van Skr. iti çruta of iti k hâta. Het is eerder het Skr. wiçruta. In het O. J. Râm. komt het zeer dikwijls voor, o. a. I, 22, IV, 3, waar de Bal. vertaling het weergeeft door kapiragi, VII, 68 (68 (Bal. vertaling kastawa) enz. Op de meeste plaatsen wordt het vertaald door Bal. kasnb (beroemd), o. a. I, 37 , IV , 50, V, 83, VI, 6 enz. Wipracinti is eene verbastering van Wipracitti, die reeds in het O. J. Âdiparwa voorkomt (vhl. B. T. L. Vk. $6^{\mathrm{e}}$ volgr. I, pag. 85).

W ugah is een woord, dat noch in het Râm. noch naar ik meen in het Mahâbhârata voorkomt wel in Bhâratay. 304. a=a göng. Vgl. Tagal. bugá, grof, dik, zwaar.

2. Rurah wordt op de plaatsen, die dr. v. d. Tuuk in zijn K. B. Wdb. aanhaalt, meestal verklaard door het Bal. rusak. Ook hier past deze vertaling, daar 't blijkbaar een synoniem van $\mathrm{dhwasta}$ en çîrnna is.

6. Mangimur moet hier beteekenen "heimelijk te werk gaan." Op andere plaatsen beteekent het "kwellen" (Râm. XXIV; 125: npangimur-imur, Bal. manggulgul) en "weggecijferd worden" (Âdip. 61: sang dewa tan kĕna inimur). Vgl. ook v.d. Tuuk, s.v.

9. Sep beteekent hier "plotseling, snel," evenals in het Âçramawâsap. pag. 48 en 52. Varianten van de daar voorkomende uitdrukking jag lis upapĕr vindt men in het Oudj. prozawerk Korawâçrama (cod. 344.2 $)$ : s e p glis up a pĕr (pag. 7l) en tap glis upapĕr (pag. 98). In 't Sund. staat kasep "schoon (van een man)" tegenover gölis "schoon (van eene vrouw)," terwijl in het O. J. beide woorden (sep en gělis) "snel" beteekenen. Vgl. ook Lamp. Pabijan-dial. hĕlaw "mooi" en Abungsch law "spoedig." 
Het overeenkomstige gedeelte van het O.J. Âdiparwan is elders door mij reeds uitgegeven en vertaald (B. T. L. Vk. $6^{\text {e }}$ volgr. 1 , pag. 85 en 87). Tevens is daar gewezen op het voorkomen van eene dergelijke legende bij de Maleisch-Polynesische volken, waaronder sommige, die nooit onder Hinduschen invloed gestaan hebben (l. c. pag. 95). Prof. Wilken heeft deze quaestie in zijn werk over het Animisme (pag. 254-256) reeds besproken. Wij laten hier ten slotte nog de plaats uit het Indische Âdiparwan (vers 1161-1166) volgen, die aan het Javaansche Âdip. tot grondslag gestrekt heeft.

Tatạ̣ pibatsu tatkâlaṃ deweșwamṛtam îpsitam, Râhur wibudharûpena dânawạ̣ prâpibat tadâ; tasya kaṇtham anuprâpte dânawasyâmṛte tadâ, âkhyâtạ̣ candrasûryyâbhyâm surânâm hitakâmyayâ.

Tato bhagawatâ tasya çirạ̣ chinnam alaṃkṛtam, cakrâyudhena cakreṇa pibato 'mṛtam ojasâ; tacchailaç̣ngggapratimạ̣ dânawasya çiro mahat, cakracchinnam kham utpatya nanâdâtibhayangkaram; tatkawandham papâtâsya wisphurad dharanîtale, saparwwatawanadwîpâm daityasyâkampyan mahîm. Tato wairawinirbandhạ̣ kṛto Râhumukhena wai, çâçwataç candrasûryyâbhyâṃ grasatyadyâpi caiwa tau.

\section{Vertaling.}

Vervolgens, toen de goden den a mṛta dronken, waarna zij verlangd hadden, dronk de dânawa Râhu in de gedaante van een god mede; toen de amṛta in de hals van den dânawa gekomen was, werd dit verteld door de zon en de maan, die het belang der goden wenschten te behartigen. Daarop werd door den met den discus gewapenden Heer ${ }^{1}$ ) het versierde hoofd van hem, terwijl hij amrta dronk, met zijn discus krachtig afgesneden; dat groote hoofd van den dânawa, op een bergtop gelijkende, vloog, door den discus afgesneden, omhoog in de lucht en brulde zeer angstwekkend; de romp van den daitya viel stuiptrekkend op den grond, terwijl hij de aarde met hare bergen, wouden en eilanden deed beven. Daarop vatte Rahu's hoofd een grenzelooze eeuwigdurende vijandschap op tegen de zon en de maan en verslindt hij hen tot nu toe.

1) n. l. W iṣnu. 